\title{
Can Innateness Ascriptions Avoid Tautology?
}

\section{Valentine Reynaud}

\section{(2) OpenEdition}

\section{Journals}

Electronic version

URL: http://journals.openedition.org/philosophiascientiae/1013

DOI: 10.4000/philosophiascientiae.1013

ISSN: $1775-4283$

\section{Publisher}

Éditions Kimé

\section{Printed version}

Date of publication: 1 October 2014

Number of pages: 177-190

ISBN: 978-2-84174-689-7

ISSN: 1281-2463

\section{Electronic reference}

Valentine Reynaud, «Can Innateness Ascriptions Avoid Tautology? », Philosophia Scientiæ [Online],

18-3 | 2014, Online since 19 January 2015, connection on 04 November 2020. URL : http://

journals.openedition.org/philosophiascientiae/1013; DOI : https://doi.org/10.4000/

philosophiascientiae.1013 


\title{
Can Innateness Ascriptions Avoid Tautology?
}

\author{
Valentine Reynaud \\ ICI Berlin (Germany) \\ Irphil, Université Lyon 3 (France)
}

Résumé : Les hypothèses sur l'innéité d'un trait formulées par les sciences cognitives - l'hypothèse d'une faculté innée de langage, par exemple - peuventelles échapper à la tautologie? Aucune définition générale de l'innéité ne semble pleinement satisfaisante. En tant que notion dispositionnelle, l'innéité rencontre le «problème de la tautologie » mis en évidence par Locke. Les jugements en matière d'innéité, qu'ils relèvent d'une théorie innéiste ou d'une théorie empiriste (puisque même les empiristes doivent en formuler), dépendent toujours d'une vision particulière du développement cognitif. Ce fait ne condamne pourtant pas ces jugements à la tautologie mais offre au contraire un critère opératoire externe qui permet de les justifier : une explication développementale jugée pertinente permettra de formuler des hypothèses solides en matière d'innéité.

Abstract: This article deals with the question whether innateness ascriptions in cognitive science-for instance, the postulation of an innate language faculty - can avoid tautology. First I shall argue that innateness is very difficult to define. As a dispositional notion, innateness faces the "problem of tautology" first outlined by Locke. Innateness ascriptions, regardless of their belonging to a nativist or an empiricist framework (indeed even empiricists have to formulate some of them), always depend on a peculiar view of cognitive development. But this fact far from condemning innateness ascriptions as tautological claims, offers an external operatory criterion to legitimise them: innateness ascriptions are justified when they rely on a satisfactory developmental explanation.

The concept of innateness has raised renewed interest since the 1950s, when Chomsky's linguistic work brought about the strong claim that the language 
faculty was innate. Many theorists have then adopted this nativist option in order to explain a wide range of skills in other domains, like the ability to understand the physical world (folk physics) or the ability to understand other minds (folk psychology). Because of the extent of nativism and the growth of rival options [Cowie 1999], the need to understand the concept of innateness has become increasingly pressing in recent years. Indeed, in spite of its prominence, it remains unclear how it ought to be understood. As a matter of fact, although the notion of innateness is widely used by biologists, cognitive scientists and philosophers, its definition remains a moot point. There is indeed no consensus on a general definition of innateness. Moreover a number of outstanding theorists have emphasized the explanatory weakness of the notion, favouring a growing scepticism among philosophers, psychologists and neuroscientists about the scientific usefulness of innateness [Karmiloff-Smith 1992], [Elman, Bates et al. 1996], [Johnson 2001], [Sterelny 2003], [Griffiths 2002]. As long as innateness is not clearly explicated, the proposal that a trait is innate amounts to admitting it is given. Innateness ascriptions, therefore, do not contribute to the elucidation of a trait's origin. As Putnam puts it:

Invoking innateness only postpones the problem of learning; it does not solve it. [Putnam 1967, 116]

In her book What's Within, Cowie holds that the hypothesis of an innate language faculty follows from our incapacity to explain cognitive development [Cowie 1999]. According to her, nativism can only be a theory by default, due to the failure of empiricism - the attempt to explain knowledge acquisition. Indeed, to what extent is the hypothesis of an innate language faculty explicative? Is it empirically testable [Goodman 1967]? How can we know whether observable linguistic behaviour is part of a maturational process or whether it is efficiently shaping linguistic knowledge? Both explanations are logically conceivable. Therefore, both positions - nativism and empiricismare logically equivalent. This is due to the fact that most innate traits are acquired and some can even be learnt. For example, it is obvious that children learn to speak. Even a nativist like Chomsky does not negate this fact. In Chomsky's hypothesis of innate grammar principles [Chomsky 1980], linguistic environment is needed for language to develop properly. Conversely, it is obvious that children need at least some innate learning mechanisms to be able to reach linguistic knowledge. Even an empiricist admits this point: Cowie's account postulates the existence of powerful learning mechanisms [Cowie 1999]. Thus, innateness ascriptions transcend the boundary between nativism and empiricism. And usual dichotomies defining innateness (innate/acquired; innate/learnt) do not tell us anything about what innateness should be.

Despite these difficulties, I will argue in this paper that innateness ascriptions can be justified and then avoid tautology. I will not deny the fact that the thinkers who resort to it run the risk of circularity since innateness ascriptions always depend on a theoretical context. But I will argue that the identification of the theoretical context they depend on-a view of cognitive 
development-offers an external operatory criterion to legitimise innateness ascriptions. Innateness ascriptions will then be justified just in case they rely on a satisfactory explanation of cognitive development, regardless of their belonging to a nativist or an empiricist framework. Therefore they do not necessarily require a commitment to nativism.

Before providing such an account, however, I begin by explaining why none of general definitions of innateness are satisfactory. I address this task in section 1. Then, I will argue in section 2 that innateness faces the problem of tautology since it is a dispositional term. Actually, innateness ascriptions in cognitive science are always dependent on a theoretical context, i.e., a view of cognitive development. Thus, a satisfactory account of development could be a way for innateness ascriptions to escape tautology, as I maintain in section 3. To this purpose, I will show that contemporary research offers some tools to elaborate such an account in section 4 . With this in mind, I conclude by highlighting the theoretical status of innateness within explanation of cognitive development.

\section{What is innateness?}

Most nativists adopt a genetic account of innateness [Pinker 1994], [Fodor 1983], [Cosmides \& Tooby 1997], [Marcus 2004], [Chomsky 1986]. Innate traits are "genetically specified" traits. But, although it is largely accepted that innateness has somehow a genetic basis, details of this implementation remain unknown. The "interactionist consensus" in life sciences [Gray 1992] establishes how the development of most phenotypic traits depends on both genetic factors and environmental factors. On the one hand, every aspect of development, learning included, consists in a regulated expression of genome. On the other hand, at every stage of a life cycle, many environmental aspects are required for phenotypic development to follow its normal course. In other terms, most phenotypic traits are both genetically specified and environmentally induced.

To say that a trait is innate cannot mean that it is present at birth or that its development does not require environmental influence. Otherwise, only rare traits that are present from the beginning of life are innate, like nuclear genes or cytoplasmic factors of the zygote. Genetic expressivity is a complex phenomenon involving the combination of several factors (including factors that regulate the expression of the genome, i.e., epigenetic factors [Morange 1998]). As a consequence, the identification of a genomic sequence as the main cause of a given phenotypic trait is rarely feasible (except for monogenic traits like genetic diseases).

For example, a couple of years ago, an English family was discovered whose several members displayed language trouble described as impairing only grammatical functions [Marcus \& Fisher 2003]. The muted copy of a gene situated on the chromosome 7 (gene FOXP2) has been identified since its hered- 
itary transmission seemed sufficient to cause the deficit. Gopnik argues for to the existence of a "gene of grammar" [Gopnik 1990], confirming thereby the Chomskyan hypothesis of innate grammar principles. But this conclusion undoubtedly relies on the neglect of the complexity of genetic expressivity. All that can be said is that the expression of the gene FOXP2 is involved in the regulation of other genes, which themselves determine the functioning of cerebral areas whose integrity is required for language development. But this does not mean that FOXP2 is exclusively dedicated to grammar encoding. Language trouble implied by FOXP2 could be only one aspect of a more general deficiency of learning. It has been shown that most genetic disorders of language are linked to non-linguistic problems (in auditory treatment or orofacial control [Karmiloff-Smith 1998]). Furthermore, in other kinds of language troubles, FOXP2 seems normal. Bird studies have also revealed that this gene is involved in birdsong learning, i.e., that it is likely to intervene in more generic process whose language is only a part of. Thus, it is very problematic to identify the presence of this gene as evidence of an innate language faculty. In a nutshell, genetic specification is not enough to provide a satisfactory definition of innateness.

Researchers have proposed other properties to define innateness, like biological adaptation, species-specificity or developmental invariance. However, these properties are both logically and empirically dissociable. Mameli \& Bateson have drawn a systematic analysis of why none of the definitions found in the literature succeed to elaborate a suitable definition of innateness [Mameli \& Bateson 2006]. Their argumentation can be summed up in the following way: in the light of their analysis, each definition turns out to be either erroneous (they describe them as "inchoate", "empty" or "counter-intuitive") or tautological (since they rely on "other controversial notions" [Mameli \& Bateson 2006, 156]). Among erroneous definitions, they include definitions in terms of non-acquisition, presence at birth or non-environmental determination that are too restrictive, and definitions in terms of genetic specification that are too flawed. Other definitions are false because they define as innate some traits that turn out to be intuitively non-innate or vice versa. For instance, it is easy to provide counter-examples against some definitions reducing innateness to species-specificity or biological adaptation [Lorenz 1965]. Species-specificity is not sufficient for innateness: some traits can be both species-specific and non-innate, like cognitive capacities. Species-specificity is not necessary for innateness either: some non species-specific traits, like eyes, are obviously innate. Similarly, being a biological adaptation is not a necessary condition for innateness: some innate traits are not adaptive, like genetic illness or the human chin. Furthermore, whether being a biological adaptation is sufficient for being innate remains a moot point.

Unfortunately, when true, general definitions ultimately rely on intuition about which trait must count as innate or non-innate, which makes them tautological or non-informative. This is the case for definitions in terms of biological maturation, developmental invariance or lack of learning. According 
to Mameli \& Bateson, these properties could always be interpreted as the products of the recurrent influence of environment. In such cases, it is always logically possible to think that allegedly innate traits are in fact non-innate and vice versa. Mameli \& Bateson conclude that every general definition of innateness is influenced by intuition invoking controversial notions (learning or maturation) that have themselves no independent definitions. Moreover, tools of critical survey seem themselves intuitively oriented. Therefore, the attempt to attribute general content to innateness seems vain.

\section{Disposition and tautology}

Yet, since "innate" denotes the implicit presence of a trait which requires some environmental cues to become explicit, innateness can be conceived as a dispositional notion. When a child is said to possess an innate faculty of language, it means that she is strongly disposed to develop language. Stich has developed such a dispositional account of innateness from the Cartesian metaphor of illness [Stich 1975]. In Notes on a Certain Program, Descartes claims that the word innate in "innate ideas" has the same dispositional meaning than in "innate diseases". Just as innate diseases go through an a-symptomatic stage before they appear, innate ideas are implicit in mind before being explicit. Symptoms, as ideas, appear during a peculiar stage. A person is not known to be ill until he displays specific symptoms. Yet, before the appearance of his symptoms, the disease has already affected him. Thus, Stich applies Descartes's account to innate beliefs and attempts to improve it in adding two conditions:

A person has a belief innately at time $t$ if, and only if, from the beginning of his life to $t$ it has been true of him that if he is or were at the appropriate age (or at the appropriate stage of life) then he has, or in the normal course of events would have, the belief occurently or dispositionally. [Stich 1975, 8]

The first added condition-"from the beginning of his life to $t$ it has been true of him that if he is or were at the appropriate age (or at the appropriate stage of life)"- aims at avoiding the case of the early acquisition of a belief (which corresponds to the case of an early bacteriological infection in the case of disease). A person is likely to formulate an idea (or contract a disease) at a certain stage of life without innately having it. The second added condition"in the normal course of events"-aims at avoiding the case of the remedy. A person could have ingested a remedy and therefore never contracted the disease by which he might have been innately affected. The same is true for beliefs: a person could have met the conditions preventing him from formulating some beliefs that he might have innately possessed otherwise.

Arguably, Stich's account provides an attractive interpretation of, say, Chomsky's theory of innate language faculty [Chomsky 1980]. According to 
this view, the linguistic environment is required for the acquisition of linguistic concepts: for instance, a child acquires from it some lexical items (words, morphemes, idiomatic sentences). With these linguistic concepts in her possession, when she comes to hear passive and active sentences, she becomes able to reach syntactic knowledge about these sentences, which is not dictated by experience: from heard passive and active sentences, she can grasp syntactic transformation properly. In other words, everything that the mind itself can form from concepts it has the opportunity to acquire, is innate. Dispositionalism seems to provide a reasonable interpretation of nativism: innate universal grammar is likely to exist whereas some people will never learn to talk.

Although highly attractive, this dispositional account remains tautological. Stich admits himself that it leads to the claim that every belief is innate. It is indeed very difficult to find a good example of innate beliefs [Stich 1975]. A philosophically famous example of these kinds of beliefs is the controversial example of the synthetic Kantian judgment. According to Kant, as is well known, the sum 12 is not contained in numerical concepts 5 and 7 but is constructed in intuition. However, is it really possible to discriminate between beliefs constructed from empirically acquired concepts and beliefs that are analytically contained in these concepts? Obviously, reaching beliefs that are analytically contained in a concept would not be evidence for innateness. It would just denote the proper understanding of the concept. In the case of language, how can we know that grammatical beliefs are formed by mind from empirically acquired linguistic concepts without being learnt from experience? Grammatical beliefs still could be a set of ad hoc rules implied by the knowledge of linguistic concepts themselves. Logically, the opposite option can still be defended [Tomasello 2003].

Thus, Stich's conception eventually relies on a controversial distinction. It raises the problem that Locke identified in An Essay Concerning Human Understanding [Locke 1689, I, 2, 4], a problem implied by the theory of innate ideas, which Locke formulates through a dilemna: either innate beliefs are present at birth and this is false; or innate beliefs are dispositional and it becomes very difficult to distinguish them from non-innate beliefs. For Locke, the notion of disposition is trivial whatever specified conditions are, as in Stich's proposal: saying that we are disposed to language would be the same as saying that we acquire language in the course of development. If the criterion for innateness is that mind can formulate some beliefs, every reached belief could be defined as innate. Similarly, contemporary anti-nativists defend both alternatives: either innateness is a false notion [Griffiths 2002] or it is tautological and non-instructive. ${ }^{1}$ The problem is precisely to find a way to attribute innate ideas to the mind before they have been formulated. Otherwise once they are formulated, they cannot be discriminated from other non-innate ideas. For

1. See for example the externalist objection formulated by Cowie [Cowie 1999] against radical concept nativism defended by Fodor [Fodor 1975, 1998]. 
Locke, it is therefore theoretically costly to postulate innate ideas because we have no criterion for recognising them.

To illustrate this difficulty, Stich compares the distinction between innate ideas and mere capacity of acquisition with the difference between a native disease and a mere natural susceptibility. The native disease will always manifest whatever would happen: necessary conditions for the appearance of the disease belong to the normal course of events. Natural susceptibility, on the contrary, will manifest in precise circumstances: some specific conditions that do not belong to the normal course of events are required. In one case, the presence of the disease is due to a specific disposition whereas in the other case, it is due to some specific conditions. This point raises the following questions: are we born to speak or only susceptible to develop language in adequate conditions? How can we know whether the occurrence of some necessary conditions for a trait to occur belongs to the normal course of events? What would happen if a special condition were extended and became the normal course of events? To take Stich's example, if a chemical component making humans ill were expanded in water, shall we consider the universally shared illness as exceptionally caused by this substance or as an innate disease?

\section{Innateness ascriptions depend on a theoretical context}

For Stich, the attribution of innate ideas depends on whether the occurrence of some conditions necessary for a cognitive trait to occur belongs to the normal course of events, i.e., whether conditions are specific ones. ${ }^{2}$ The point I want to stress is that specific conditions and rare conditions are to be separated. What counts for innateness ascriptions is not the rarity or the frequency of environmental conditions in which cognitive traits appear but whether environmental cues have an informational role in shaping them or a mere triggering role in activating them. Truly, the frequency of conditions can be instructive when a trait is present in all conditions (including very poor conditions). For example, the development of species-specific birdsong in individuals raised in silence reveals the innateness of the song in the given species [Lorenz 1965]. However, cognitive traits are present in some conditions but not in all. For example, language is not present in a mere vital environment [Pinker 1994]. Yet, this fact does not mean anything about its (non-)innateness. Language needs more specific conditions to develop - a linguistic environment-but it can still be an innate faculty. In a nutshell, the debate about linguistic nativism does not question whether environment is needed or not for development; it deals with the role of environmental cues.

2. The use of "normal course of events" is obviously problematic. Arguably, there is much that could be done in order to elaborate and clarify this expression. For present purposes, however, I leave such matters of detail to one side. 
The role attributed to environment (triggering or informational) depends on the view of two other features, namely learning mechanisms (more or less powerful) and the final state of development (the knowledge to reach). Every innateness ascription relies on a peculiar view of cognitive development. Consider language again. The nativist position of Chomsky defines the final state of linguistic knowledge as a set of abstract and complex grammar principles; learning mechanisms as inductive ones; linguistic environment as a set of poor cues [Chomsky 1980]. With such definitions, learning inductively a set of abstract and complex grammar principles with few instructions becomes impossible. Chomsky concludes that humans are necessarily endowed with an innate faculty of language (a set of innate principles) - otherwise language learning is impossible to understand. This is the argument from the poverty of stimulus [Chomsky 1980]. The rival empiricist position of Cowie purports to show that the resources available to the child are richer, learning mechanisms are more powerful and holistic, and the final state of knowledge is more simple and labile [Cowie 1999]. Innate biases and strategies applying constraints on perception and learning are sufficient to acquire language.

Since these components are interdependent, both argumentations in favour or against the innate faculty of language have been said to be circular. The argument from the poverty of stimulus has been criticised in the following way: since the nature of language knowledge attributed to the child determines the explanation of her acquisition (as an actualisation of innate disposition), how can it avoid tautology? How can we demonstrate the innateness of syntactic knowledge that is first needed to define language knowledge [Putnam 1967], [Goodman 1967], [Pullum \& Scholz 2002]? Conversely, the empiricist notion of general learning mechanisms has been judged obscure and not explanatory. Generalisation is a trivial notion regarding the intrinsic structure of language acquisition device [Chomsky 1967]. Atran, for example, claims that "learning syntactic structures through 'social interaction' is no more plausible an alternative than learning by 'osmosis'" [Atran 2001].

However, I maintain that saying that innateness ascriptions always depend on a specific theoretical context does not condemn them as tautological claims. Indeed, accounts of environment, learning mechanisms and final state of knowledge belong to a specific view of cognitive development. Thus, it would be enough to elaborate a satisfactory view of cognitive development to justify innateness ascriptions. The suitability of a nativist or an empiricist position about a trait entirely relies on the relevance of the developmental story it offers for this trait. For example, the Chomskyan hypothesis of innate grammar principles relies on a maturational view of linguistic development that interprets the acquisition of an isolated grammar construction by the child as an evidence for the knowledge of a corresponding rule [Chomsky 1980]. Thus the appreciation of this innateness ascription depends on the relevance of the Chomskyan account of linguistic development. This means that we shall confront this account with recent data on linguistic development. For example, some developmental data seem to show that learning specific expressions does 
not involve an immediate effect of generalisation, as Chomsky seems to suppose. When the child learns the expression "close the window", she is not immediately able to apply the rule [close + object] to other cases (with different objects) [Tomasello 2003]. If this is true, Chomskyan innateness ascription is not fully justified.

To sum up, innateness is a developmental notion in the sense that innateness ascriptions are always formulated within a particular account of cognitive development [Wimsatt 1986], [Reynaud 2013]. Since innateness ascriptions are never independent from the specific vision of development within which they take place, the more we know about development, the more innate ascriptions are justified.

\section{Cognitive developmental explanation and innateness}

It appears that innateness ascriptions are justified only when they rely on a satisfactory explanation of development. But is it really possible to provide such an explanation without being guided by the intuition of what counts as innate and what counts as non-innate? According to developmental system theorists [Griffiths 2002], development is so complex that every attempt to understand it in partitioning genetic cause and environmental cause fails: this is the main reason why we should renounce innateness.

Obviously, a general theory of development is not feasible. It is no longer possible to see development as a linear and homogeneous succession of steps leading to the development of logical thought as Piaget did [Piaget 1975]. Developmental psychologists have highlighted that cognitive development is domain specific [Hirschfeld \& Gelman 1994]. Moreover, as has been noticed in section 1 , the general point of view increases the risk of tautology. The explanation of cognitive development necessarily seeks of an elaboration of peculiar developmental trajectories of specific traits. Surely, such elaboration must rely on data from developmental sciences (developmental biology, developmental psychology, but also developmental evolutionary biology, computational developmental psychology, developmental evolutionary psychology and cognitive developmental neuroscience). As Ariew claims, developmental biology makes it possible to empirically study the way environmental systems react to specific environmental cues and to grasp some developmental differences between organisms in elaborating typical developmental patterns [Ariew 2007]. Innateness ascriptions are among answers to the question: what difference does the absence, the presence or the fluctuations of some environmental parameters make on the development of a trait? Yet, according to Ariew, innateness ascriptions can be made without causal stories. However, the interpretation of some empirical data remains ambiguous in the case of most cognitive traits. Surely isolation experiments are operatory to establish 
innateness when traits develop in very poor conditions (like species-specific birdsong in some species). But for all other cases, when traits need some more specific conditions to appear (like language), the question of the role of environmental cues is raised. The elaboration of developmental scenarios is not- I maintain -independent of a causal story [Reynaud forthcoming].

It is then necessary to investigate causal mechanisms underlying development. However, this seems to be a difficult task, since development implies several developmental resources interacting in complex and cumulative ways. But contemporary research offers some tools to investigate these causal mechanisms and to clarify the notion of cognitive developmental explanation. The mechanistic account of explanation [Bechtel 2002] seems to provide a relevant framework to elaborate developmental scenarios. A mechanism is a composite system characterised by the global activity it realises [Bechtel \& Adele 2009]. This global activity can be decomposed in operations and components (that can be themselves decomposed) whose interaction produces the given phenomenon. Then, the mechanistic approach recognises the potential of selforganisation and emergence proper to cognitive development [Bechtel \& Adele 2009]. Cognitive development is indeed characterised by a growing complexity of organisation where new structures and functions emerge in the course of time [Gottlieb, Wahlsten et al. 2006]. The advantage of the mechanistic approach is that operations and components can be identified without reducing holistic properties of the global system. Ontological emergence is then compatible with etiological investigation operating decomposition [Bechtel 2002].

Cognitive developmental explanation is a decomposition of cognitive development into interactive components and operations in order to elaborate specific developmental scenarios. For this purpose, the mechanistic framework promotes the use of modeling. Connexionist networks, probabilistic and statistical models and models from developmental system theory are very useful to test hypotheses on the nature of learning. ${ }^{3}$ But, the essential point is that developmental decomposition has to rely on developmental criteria and not on logical ones. Gerrans denounces a logical view of cognitive development that establishes developmental steps as necessary and sufficient conditions leading to the development of a specific cognitive trait [Gerrans 1998]. A satisfactory developmental decomposition has to show how each stage is specifically required for the development of the subsequent stage in identifying its developmental role.

Ideally the mechanistic account would be able to articulate different levels, cognitive and neural (or genetic) in elaborating a cascade of more and more precise mechanical decompositions. But the explanatory gap between structural (genetic and neural) level and functional (cognitive) level for cognitive traits is significant [Frith \& Morton 2001]. Cognitive development has to be

3. See for example the simple recurrent network in [Lewis \& Elman 2001] that explores the possibility of extracting hierarchical structures form primary linguistic data. 
investigated first at a functional level. ${ }^{4}$ Mechanism is not only a neurological structure fulfilling an activity; it also can be interpreted in functional sense, as a structure fulfilling a specific task [Hacking 2001].

With this in mind, innate endowment of organisms is to be assimilated with endogenous components and operations that an explanatory approach of development displays. Contemporary theorists abundantly employing this concept use it in a theoretical context that postulates a developmental scenario for such capacities. They refer to these capacities as a terminus a quo, until something better turns up. Innate endowment is then what stands up to developmental explanation, i.e., what developmental processes cannot explain further, what is developmentally primitive. ${ }^{5}$ In other terms, innate entities have to be conceived as primitive functional entities [Frith \& Morton 2001] posited by empirically robust and explicit developmental scenarios. These entities could be domain specific, general purpose or simply domain dominant [Buller 2005], since innateness ascriptions are not necessarily nativist (e.g., domain specific) ones. Moreover, since innateness ascriptions are elaborated at a functional level, the complexity of genetic expressivity is not a stumbling block to their formulation. If this is true, an operatory criterion for formulating non-tautological innateness ascriptions becomes available: justified innateness ascriptions are the ones that rely on a satisfactory developmental explanation.

\section{Bibliography}

A RIEw, André [2007], Innateness, in: Handbook of the Philosophy of Science - Philosophy of Biology, edited by M. Matthen \& C. Stephens, Amsterdam: North-Holland, Handbook of the Philosophy of Science, vol. 3, 567-584, doi:10.1016/B978-044451543-8/50026-5.

Atran, Scott [2001], The case for modularity: Sin or salvation?, Evolution and Cognition, 7, 46-55.

Bechtel, William [2002], Decomposing the mind-brain: A long-term pursuit, Brain and Mind, 3(2), 229-242, doi:10.1023/A:1019980423053.

Bechtel, William \& Adele, Abrahamsen [2009], Mechanistic explanation and the nature-nurture controversy, Bulletin d'Histoire et d'Epistémologie des Sciences de la Vie, 12, 75-100.

Buller, David [2005], Adapting Minds: Evolutionary Psychology and the Persistent Quest for Human Nature, Cambridge, MA: MIT Press.

4. This does not mean of course that structural data are not instructive for understanding cognitive development.

5. Innate endowment is not only what it is "generatively entrenched" as Wimsatt says [Wimsatt 1986]. 
Chomsky, Noam [1967], Recent contributions to the theory of innate ideas, Synthese, 17(1), 2-11, doi:10.1007/BF00485013.

— [1980], Rules and Representations, Cambridge, MA: MIT Press.

- [1986], Knowledge of Language: Its Nature, Origin, and Use, New York: Praeger Publishers.

Cosmides, Leda \& Tоовy, John [1997], Evolutionary psychology: A primer, www.psych.ucsb.edu/research/cep/primer.html.

Cowie, Fiona [1999], What's Within? Nativism Reconsidered, Oxford: Oxford University Press.

Elman, Jeffrey, Bates, Elizabeth, Johnson, Mark, Karmiloff-Smith, Annette, PArisi, Domenico, \& PlunketT, Kim [1996], Rethinking Innateness. A Connectionist Perspective on Development, Cambridge, MA: MIT Press.

Fodor, Jerry [1975], The Language of Thought, Sussex: Harvester Press.

— [1983], The Modularity of Mind, Cambridge, MA: MIT Press.

[1998], Concepts: Where Cognitive Science Went Wrong, New York: Oxford University Press.

Frith, Uta \& Morton, John [2001], Why we need cognition: cause and developmental disorder, in: Language, Brain and Cognitive Development, edited by E. Dupoux, Cambridge MA: MIT Press, 263-278.

Gerrans, Philip [1998], The norms of cognitive development, Mind \& Language, 13(1), 56-75, doi:10.1111/1468-0017.00065.

Goodman, Nelson [1967], The epistemological argument, Synthese, 17(1), 2328, doi:10.1007/BF00485015.

Gopnik, Myrna [1990], Genetic basis of grammar defect, Nature, 347(6288), 26, doi:10.1038/347026a0.

Gottlieb, Gilbert, Wahlsten, Douglas, \& Lickliter, Robert [2006], The significance of biology for human development: A developmental psychobiological systems view, in: Handbook of Child Psychology, edited by W. Damon \& R. Lerner, New York: Wiley, vol. 1, 210-257, doi:10.1002/9780470147658. chpsy0105.

Gray, Russell [1992], Death of the gene: Developmental systems strike back, in: Trees of Life, edited by P. Griffiths, Dordrecht: Kluwer, Australasian Studies in History and Philosophy of Science, vol. 11, 165-209, doi:10.1007/ 978-94-015-8038-0_7. 
Griffiths, Paul E. [2002], What is innateness?, The Monist, 85(1), 70-85, doi:10.5840/monist 20028518 .

HaCking, Ian [2001], Aristotelian categories and cognitive domains, Synthese, 126(3), 473-515, doi:10.1023/A:1005221431872.

Hirschfeld, Lawrence \& Gelman, Susan [1994], Toward a topography of mind: An introduction to domain specificity, in: Mapping the Mind. Domain Specificity in Cognition and Culture, edited by L. Hirschfeld \& S. Gelman, Cambridge: Cambridge University Press, 3-36, doi:10.1017/ CBO9780511752902.002.

Johnson, Mark H. [2001], Functional brain development in humans, Nature Reviews Neuroscience, 2(7), 475-483, doi:10.1038/35081509.

Karmiloff-Smith, Annette [1992], Beyond Modularity : A developmental perspective on cognitive science, Cambridge, MA: MIT Press.

[1998], Development itself is the key to understanding developmental disorders, Trends in Cognitive Sciences, 2(10), 389-398.

Lewis, John D. \& Elman, Jeffrey L. [2001], Learnability and the statistical structure of language: Poverty of stimulus arguments revisited, in: Proceedings of the 26th Annual Boston University Conference on Language Development, Somerville, MA: Cascadilla Press, 359-370.

Locke, John [1689], An Essay Concerning Human Understanding, Oxford: Oxford University Press, edited by P. H. Nidditch, 1975.

Lorenz, Konrad [1965], Evolution and Modification of Behavior, Chicago: University of Chicago Press.

Mameli, Matteo \& Bateson, Patrick [2006], Innateness and the sciences, Biology and Philosophy, 21(2), 155-188, doi:10.1007/s10539-005-5144-0.

Marcus, Gary [2004], The Birth of the Mind: How a Tiny Number of Genes Creates the Complexities of Human Thought, New York: Basic Books.

Marcus, Gary \& Fisher, Simon [2003], FOXP2 in focus: What can genes tell us about speech and language?, Trends in Cognitive Science, 7(6), 257-262, doi:10.1016/S1364-6613(03)00104-9.

Morange, Michel [1998], La Part des gènes, Paris: Odile Jacob.

Piaget, Jean [1975], L'équilibration des structures cognitives : problème central du développement, Paris: PUF.

PINKER, Steven [1994], The Language Instinct, New York: William Morrow and Co. 
Pullum, Geoffrey K. \& Scholz, Barbara C. [2002], Empirical assessment of stimulus poverty arguments, The Linguistic Review, 18(1-2), 9-50, doi: 10.1515/tlir.19.1-2.9.

Putnam, Hilary [1967], The 'innateness hypothesis' and explanatory models in linguistics, Synthese, 17(1), 12-22, doi:10.1007/BF00485014.

Reynaud, Valentine [2013], L'innéité à l'épreuve de la complexité du développement, in: L'Innéité aujourd'hui, edited by D. Forest, Paris: Éditions matériologiques.

— [forthcoming], Innéité et canalisation du développement biologique, Repha.

Sterelny, Kim [2003], Thougth in a Hostile World : The Evolution of Human Cognition, Oxford: Blackwell.

Stich, Stephen [1975], The idea of innateness, in: Innate Ideas, edited by S. Stich, Berkeley: University of California Press, 1-22.

Tomasello, Michael [2003], Constructing a Language. A Usage-Based Theory of Language Acquisition, Cambridge, MA: Harvard University Press.

Wimsatт, William [1986], Developmental constraints, generative entrenchment, and the innate-acquired distinction, in: Integrating Scientific Disciplines, edited by W. Bechtel, Dordrecht: Martinus Nijhoff, 185-208. 